\title{
PALEOMAGNETISMO E IDADES K-AR DO COMPLEXO INTRUSIVO ITAQUI, ESTADO DE SÃO PAULO
}

\author{
PAULO DE BARROS CORREIA* \& MÁRCIA ERNESTO**
}

\begin{abstract}
PALAEOMAGNETISM AND K-AR AGES OF THE ITAOUI INTRUSIVE COMPLEX, STATE OF SÃO PAULO Paleomagnetic studies of the Itaqui Granitoid Complex (State of São Paulo) of Brasiliano age allowed the identification of three characteristic magnetizations (Gl, G2 and G3). In ali cases titanomagnetites with Curie temperatures around $585^{\circ} \mathrm{C}$ are the remanence carriers. The corresponding paleomagnetic poles are Gl $\left(41.0^{\circ} \mathrm{E} 44.2^{\circ} \mathrm{S} ; \mathrm{N}=8, \alpha_{95}=14.8^{\circ}\right), \mathrm{G} 2\left(67.8^{\circ} \mathrm{E} 16.6^{\circ} \mathrm{S} ; \mathrm{N}=9, \alpha_{95}=10.9^{\circ}\right)$ and $\mathrm{G} 3\left(159.6^{\circ} \mathrm{E} 83.6^{\circ} \mathrm{N}\right.$; $\mathrm{N}=18, \alpha_{95}=9 \cdot 6^{\circ}$ ). K-Ar data of three samples from three diferent lithologic units of the complex yelded ages varying from 540 to $520 \mathrm{Ma}$. Poles Gl and G2 are in accordance with apparent polar wander curves proposed for Africa during the interval 600-550 Ma. However, pole G3 seems to be related to a secondary magnetization imparted by the Mesozoic tectono-magmatic events. The distribution of the Gl and G2 magnetizations throughout the complex, and the time-relationship between the various rock units suggest that G2 is slightly older than Gl.
\end{abstract}

Keywords: Itaqui Intrusive Complex, paloemagnetism, K-Ar dating, granitoid

RESUMO Estudos paleomagnéticos do Complexo Itaqui, Estado de São Paulo, baseados em 92 sítios (171 amostras orientadas) das unidades Barueri, Aldeia da Serra, Pedreira Cantareira, Torre, Mutinga e Suru, permitiram identificar três direções paleomagnéticas características, que correspondem aos pólos paleomagnéticos $\mathrm{Gl}\left(41.0^{\circ} \mathrm{E} 44.2^{\circ} \mathrm{S} ; \mathrm{N}=8, \alpha_{95}=14.8^{\circ}\right), \mathrm{G} 2\left(67.8^{\circ} \mathrm{E} 16.6^{\circ} \mathrm{S} ; \mathrm{N}^{\circ}=9, \alpha_{95}=10.9^{\circ}\right)$ e $\mathrm{G} 3$ $\left(159.6^{\circ} \mathrm{E} 83.6^{\circ} \mathrm{N} ; \mathrm{N}=18, \alpha_{95}=9.6^{\circ}\right)$. Idades $\mathrm{K}-\mathrm{Ar}$ obtidas para as unidades Barueri, Aldeia da Serra e Mutinga, variam entre 520 e $540 \mathrm{Ma}$. Os pólos G 1 e G2 são coerentes com as curvas de deriva polar aparente propostas para a África, no intervalo $550-600$ Ma. Entretanto, o pólo G3 parece indicar uma remagnetização ocorrida durante os eventos tectono-magmáticos do Mesozóico. A existência de dois pólos distintos, Gl e G2, para o Complexo Itaqui, está de acordo com modelos evolutivos segundo os quais a colocação do granito Barueri precede a colocação do granito Aldeia da Serra. A distribuição das componentes de magnetização Gl e G2 no complexo e a relação temporal entre as várias unidades de rocha, sugerem que a componente $\mathrm{G} 2$ seja um pouco mais velha que $\mathrm{G} 1$.

Palavras-chave: Complexo Intrusivo Itaqui, paleomagnetismo, datação K-Ar, granitóide

INTRODUÇÃO Nos últimos anos tem havido um crescente interesse nos estudos magnéticos de rochas graníticas, quer na sua classificação, por meio da susceptibilidade magnética associada à mineralogia magnética (Ishihara 1981), quer no estudo paleomagnético para obtenção de direções da remanescência magnética (Hattinh 1990). Entretanto, a maior atenção tem sido voltada aos aspectos estruturais relacionados à colocacão dos corpos graníticos, evidenciados pela anisotropia de susceptibilidade magnética (e.g. Ellwood e Whitney 1980, Bouchez et al. 1990, Archanjo et al. 1994, Olivier \& Archanjo 1994, Correia 1994).

No Brasil, poucos corpos graníticos foram alvo de estudos paleomagnéticos, tendo sido investigados até o momento, apenas os granitos arqueanos Carajás e Seringa, do Craton Amazônico (Renne et al. 1988) e o granito cambriano Ramada, do cinturão Ribeira (D'Agrella Filho $\&$ Pacca 1988). No que tange à caracterização magnética de granitos, pode-se citar os trabalhos de Magalhães e Dall'Agnol (1992) e Magalhães et al. (1994), em granitos arqueanos da Amazônia.

Do ponto de vista do paleomagnetismo, os granitóides são rochas potencialmente interessantes, quando sua mineralogia magnética é apropriada à retenção de uma magnetização estável. Particularmente para os estudos do Neoproterozóico da placa Sul-Americana, cuja base de dados paleomagnéticos é ainda muito pobre, rochas graníticas, que ocorrem em abundância, podem representar uma fonte de dados importante. Os granitóides constituem um dos componentes mais notáveis da região Sudeste do Brasil, e são considerados em sua quase totalidade, como produtos do Ciclo Brasiliano/Pan-Africano. Somente no Estado de São Paulo, cerca de 30\% da área do seu embasamento consiste de granitóides intrusivos relacionados ao Neoproterozóico (Janasi\&Ulbrichl991)

No presente trabalho, são apresentados os resultados dos estudos paleomagnéticos realizados no Complexo Granitóide Itaqui, situado entre as cidades de Barueri e Santana do Parnaiba, na região metropolitana de São Paulo. Estes dados são parte de um projeto mais abrangente (Correia 1994), em que se procurou associar dados da remanescência magnética, anisotropia magnética e mineralogia, para investigar o modo de colocação do complexo Itaqui e contribuir para a definição da trajetória polar da América do Sul ao final do Proterozóico.

ASPECTOS GEOLÓGICOS A suite intrusiva Itaqui abrange uma área de $120 \mathrm{~km}$ e suas porções oeste, noroeste, norte e parte da porção nordeste intrudem os metamorfitos do Grupo São Roque. A porção sul e parte da nordeste são limitadas, respectivamente, pelas zonas de cisalhamento Taxaquara e Vila Menck (Fig. 1).

O Complexo Itaqui, de caráter poli-intrusivo (Ferreira \& Wernick 1991), compõe-se de quatro unidades principais que são o granodiorito
Barueri e os monzogranitos Pedreira Cantareira, Aldeia da Serra e Mutinga. Subordinadamente, também diques tais como os monzogranitos Suru e Torre e o quartzo-monzonito Cruz Preta. Uma síntese completa dos aspectos evolutivos da Complexo Itaqui é apresentada por Ferreira (1996). Do ponto de vista geocronológico, o complexo Itaqui é considerado tardi-orogênico (Ferreira 1996). Dados radiométricos (Ferreira 1996 e referências citadas) para outros corpos graníticos da mesma área, indicam que essa granitogênese é de idade neoproterozóica (700-495 Ma).

O Complexo está afetado pelas zonas de cisalhamento brasilianas de Taxaquara e Vila Menck. A gênese do Complexo Itaqui está ligada à própria origem da orogênese Brasiliana/Pan-Africana, que afetou as regiões sudeste do Brasil e de Damara, no oeste africano. Segundo Brito Neves \& Cordani (1991), os domínios Brasiliano/Pan-africano podem ser considerados como consequência da complexa colisão e ajustamento de cinco grandes massas continentais, que são os Crátons Âmazônico, Oeste Africano, Congo-Kasai/São Francisco, Rio de La Plata e do Kalahari. Esta colisão teria provocado um feixe anastomosado de falhas, inclusive as de Taxaquara, Jundiuvira, Cubatão e outras, no sudeste brasileiro (Wernick \& Ferreira 1992). A elas associam-se manifestações de magmatismo cálcio-alcalino de baixa, média e alta temperatura, subalcalinos potássicos, alcalinos e peraluminosos (Wernick \& Galembeck 1985, 1986 e 1987, Wernick 1984, 1990).

De acordo com Ferreira (1991), o granodiorito Barueri apresenta uma textura porfíítica, marcada pela presença abundante de megacristais de K-feldspato, de 1,5 a $8 \mathrm{~cm}$, em uma matriz média a grossa. $\mathrm{O}$ monzogranito Pedreira Cantareira tem uma matriz média a grossa, inequigranular, com raros megacristais de K-feldspato, de 2 a $8 \mathrm{~cm}$. A unidade Aldeia da Serra é caracterizada por uma matriz granular média, com poucos megacristais de K-feldspato, de 1 a $2 \mathrm{~cm}$. O granito Mutinga é leucocrático, cinza esbranquiçado e apresenta uma matriz fina equigranular, com raríssimos fenocristais de K-feldspato. O monzogranito Torre é esbranquiçado e caracterizado por uma matriz de textura equigranular fina a média. O monzogranito Suru é hololeucocrático e apresenta textura equigranular fina a média. O quartzomonzonito Cruz Preta tem uma matriz granular média a fina, com frequentes megacristais de $\mathrm{K}$-feldspato frequentes, de $0,5 \mathrm{a} 1,5 \mathrm{~cm}$.

PROCEDIMENTO EXPERIMENTAL Amostragem A

amostragem do Complexo Itaqui foi efetuada coletando-se blocos orientados ou extraindo-se testemunhos orientados com amostrador portátil. Foram amostrados 92 sítios perfazendo um total de 171 amostras. A orientação das amostras foi feita, sempre que possível, com bússola magnética e solar.

A figura 2 mostra o mapa de pontos de amostragem, cuja distribuição é irregular devido principalmente à falta de afloramentos

* Departamento de Engenharia de Minas/UFPE, Rua Académico Hélio Ramos s/n, 50740-530 Recife - PE

** Autor responsável pela correspondência: Instituto Astronómico e Geofísico/USP, Rua do Matão, 1226 - Cidade Universitária, 05580-900 São Paulo, SP, Tel.: 818-4755; Fax: 8185034, e-mail: mareia Ciag.usp.br 

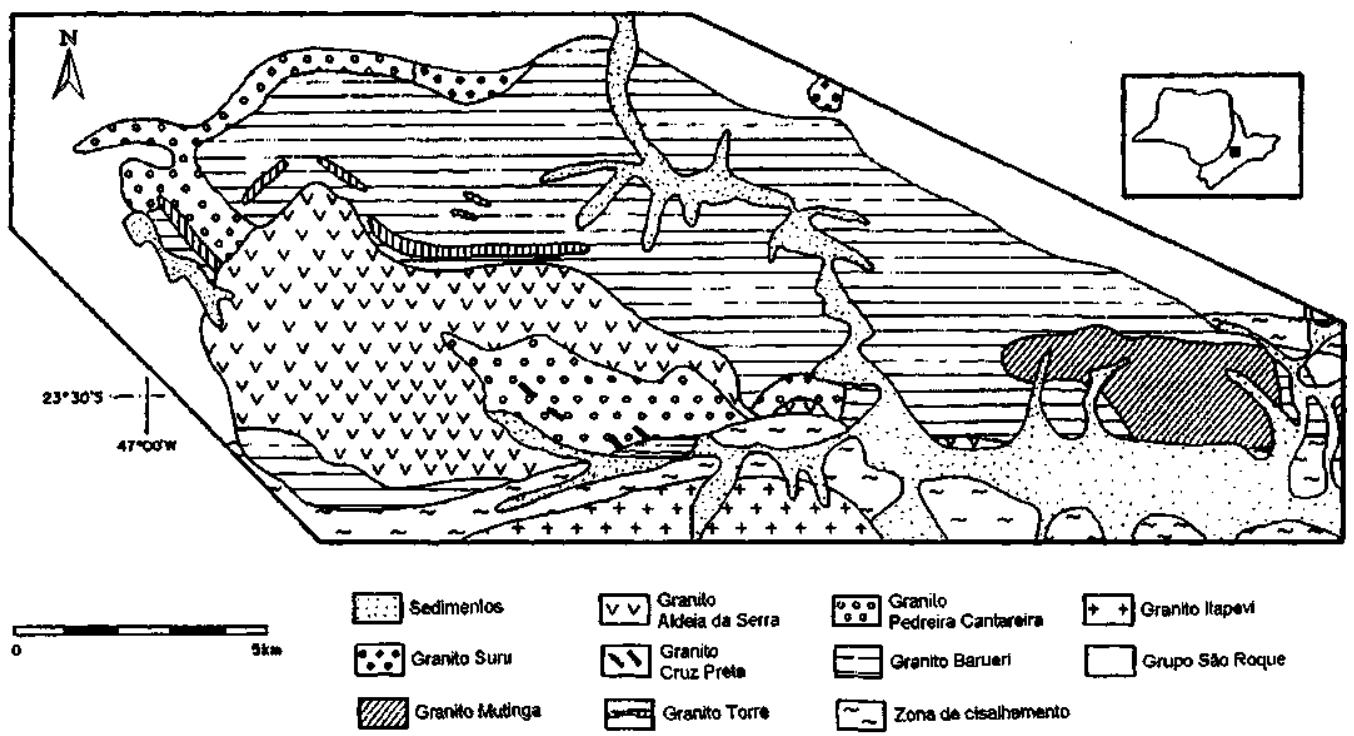

Figura I - Mapa geológico do Complexo Itaqui (baseado em Ferreira 1991).

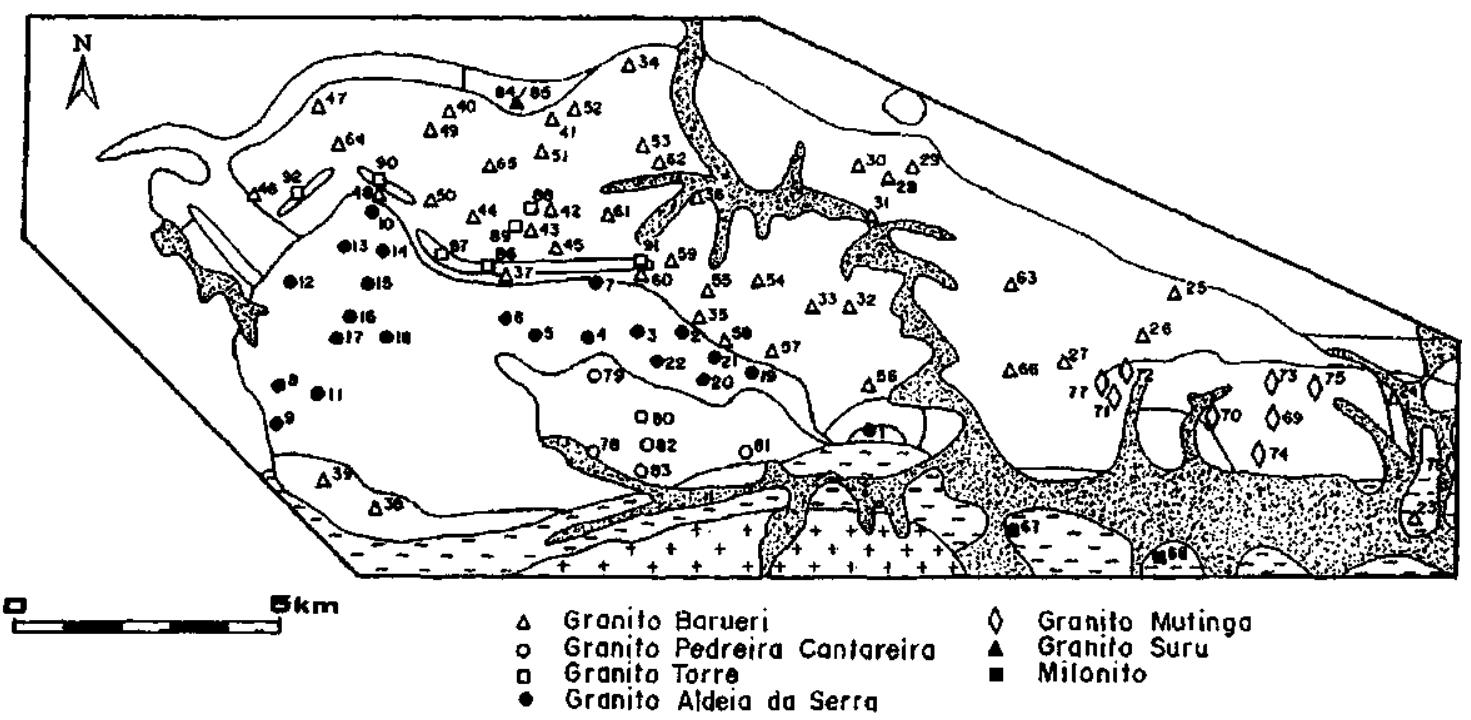

Figura 2 - Mapa de pontos de amostragem.

apropriados (somente blocos que podem ter rolado) em algumas áreas, e à própria situação geográfica do complexo, que se encontra em grande parte, principalmente no leste, na região urbana da cidade de Barueri. Por outro lado, na porção oeste do maciço a densidade de afloramentos é boa, mas a sua distribuição é concentrada mais a norte. A sul (sudoeste do maciço), a falta de amostras do granito Aldeia da Serra deve-se à falta de afloramentos adequados e também à dificuldade de acesso à área. Na zona milonítica, somente dois afloramentos puderam ser amostrados.

Medidas da MRN e verificação da estabilidade magnética Para as medidas de remanescência magnética, as amostras foram preparadas em cilindros com $2,5 \mathrm{~cm}$ de diầmetro e 2,2 $\mathrm{cm}$ de altura. A maioria das medidas da magnetização remanescente foi efetuada com um magnetômetro rotativo Molspin Ltd., sendo que cerca de 5\% das amostras foram medidas no magnetômetro criogênico$2 \mathrm{G}$ Enterprises. Neste último, foram analisadas as amostras mais fracamente magnéticas, dentre as quais algumas já haviam sido medidas no magnetômetro Molspin, sem resultados. No total foram analisados 374 espécimens.

Inicialmente, mediu-se a intensidade da magnetização remanescente natural (MRN) das amostras e, a seguir, testou-se a estabilidade da magnetização remanescente, por meio de desmagnetizações sucessivas utilizando-se campos magnéticos alternados. A desmagnetização térmica restringiu-se a menos de $10 \%$ das amostras, devido ao comportamento aleatório do vetor magnetização durante esse processo, verificado na maioria dos casos. Na desmagnetização por campos alternados (Fig. 3), utilizou-se o desmagnetizador SI-4 da Saphire Instruments, cujo campo máximo é de $200 \mathrm{mT}$. As amostras-piloto foram submetidas inicialmente a um campo de $2,5 \mathrm{mT}$, com incrementos gradativos de $2,5 \mathrm{mT}$ até atingir-se $20 \mathrm{mT}$, a intervalos de $5 \mathrm{mT}$ até $50 \mathrm{mT}$ e, finalmente, a intervalos de $10 \mathrm{mT}$ até $100 \mathrm{mT}$. As amostras mais estáveis foram submetidas, ainda, a campos de até $200 \mathrm{mT}$ em intervalos de $20 \mathrm{mT}$.

$\mathrm{Na}$ desmagnetização térmica (Fig. 3) as amostras foram previamente desmagnetizadas em campos alternados de $10 \mathrm{mT}$. A desmagnetização térmica processou-se no intervalo de temperatura de $200^{\circ} \mathrm{C}$ a $500^{\circ} \mathrm{C}$, com incremento de $50^{\circ} \mathrm{C}$ e, quando necessário, atingiu-se a temperatura máxima de $670^{\circ} \mathrm{C}$ com incremento de $30^{\circ} \mathrm{C}$. Entretanto, a desmagnetização térmica não foi tão eficiente quanto a desmagnetização por campos alternados, resultando muitas vezes num comportamento aleatorio do vetor magnetização. Por isto optou-se pelo método de campos alternados, cujos resultados foram mais coerentes e sempre ocorreu a desmagnetização completa das amostras.

Identificação da magnetização característica Em geral, pelo menos três espécimens de cada amostra foram analisados. Entretanto, de alguns sítios não foi possível obter mais do que dois 

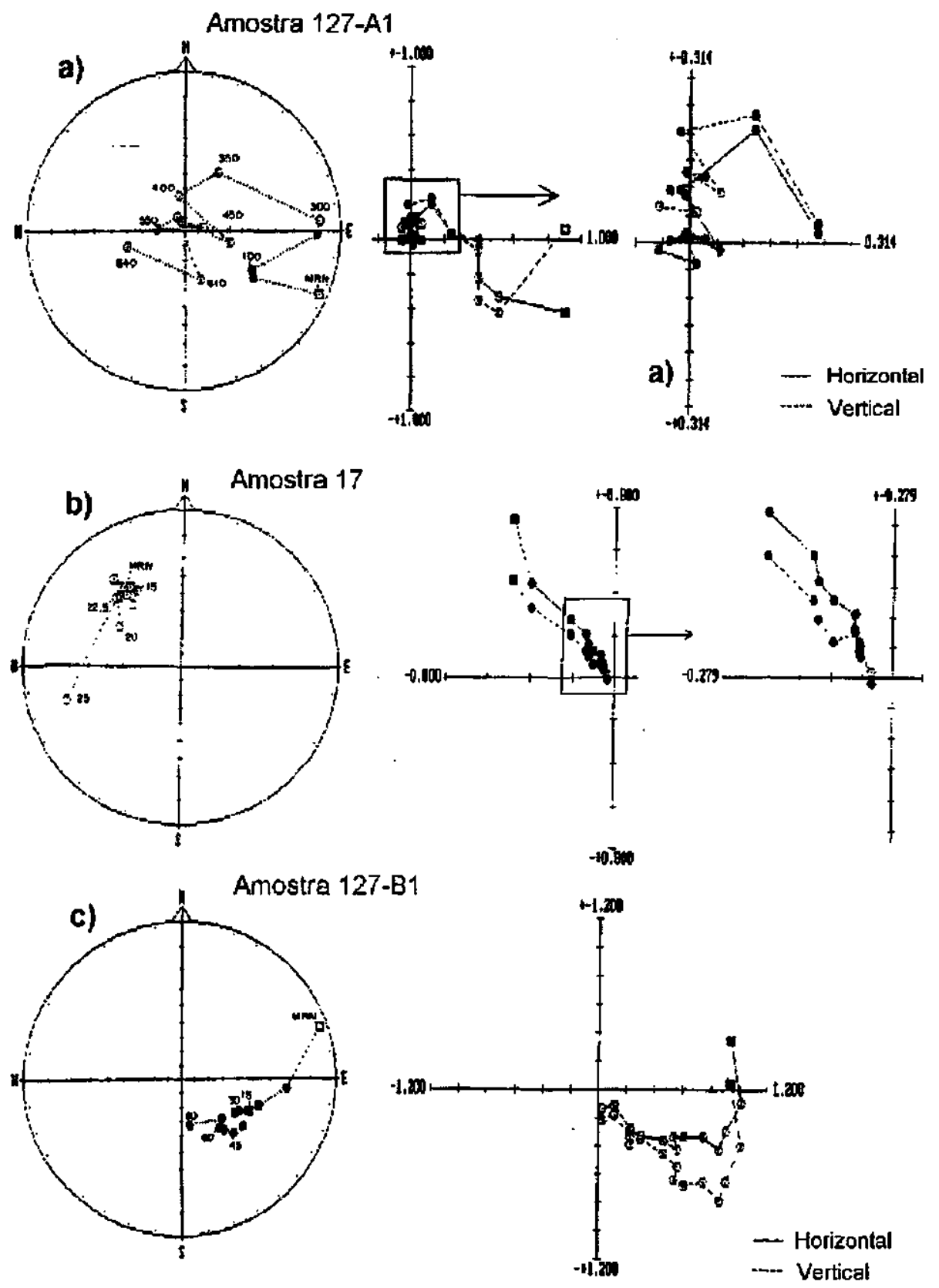

Figura 3 - Exemplos do comportamento magnético das amostras durante a desmagnetização por campos magnéticos alternados e térmica.

espécimens. Os resultados da desmagnetização foram analisados em diagramas vetoriais de Zijderveld (1967) e a separação das componentes de magnetização foi feita pelo método dos mínimos quadrados de Kirshvink (1980). Na maioria dos casos, os resultados não mostraram mais de uma componente importante de magnetização (Fig. 3), embora uma componente de origem viscosa fosse geralmente detectada. Algumas amostras apresentaram comportamento de multicomponente, mas não foram identificadas componentes características de menor coercitividade.

As direções médias das magnetizações características (Tabela 1) de cada sítio, foram calculadas dando-se peso unitário aos espécimens correspondentes e utilizando-se a estatística de Fisher (1 953). Os pólos geomagnéticos virtuais (PGVs), correspondentes a essas direções médias, também estão na Tabela 1. Resultados satisfatórios foram obtidos em apenas 59 sítios, sendo que as unidades mais favoráveis foram os granitóides Barueri e Aldeia da Serra. Mesmo assim, em muitos sítios, apenas dois espécimens apresentaram resultados coerentes. Cerca de 30 amostras de uma pedreira em exploração no granito Pedreira Cantareira, foram abandonadas devido à fraca intensidade de magnetização e instabilidade magnética. Os demais sítios não apresentaram estabilidade magnética ou nenhuma coerência de resultados. Este fato está, em parte, associado à variação da susceptibilidade magnética nos diversos sítios (Tabela 1), sendo que em alguns deles há ausência ou escassez de minerais magnéticos.

Um número considerável de sítios (cerca de 30\%) apresentou resultados pouco coerentes, embora individualmente as amostras tivessem boa estabilidade magnética. Resultados destes sítios não foram incluídos na Tabela 1. Considerando-se que para alguns sítios o círculo de confiança $\left(\sigma_{95}\right)$ é muito elevado (até $78,2^{\circ}$ ), decidiu-se selecionar os dados restringindo a $30^{\circ}, \mathrm{o} \sigma_{95}$ máximo. Neste caso, 


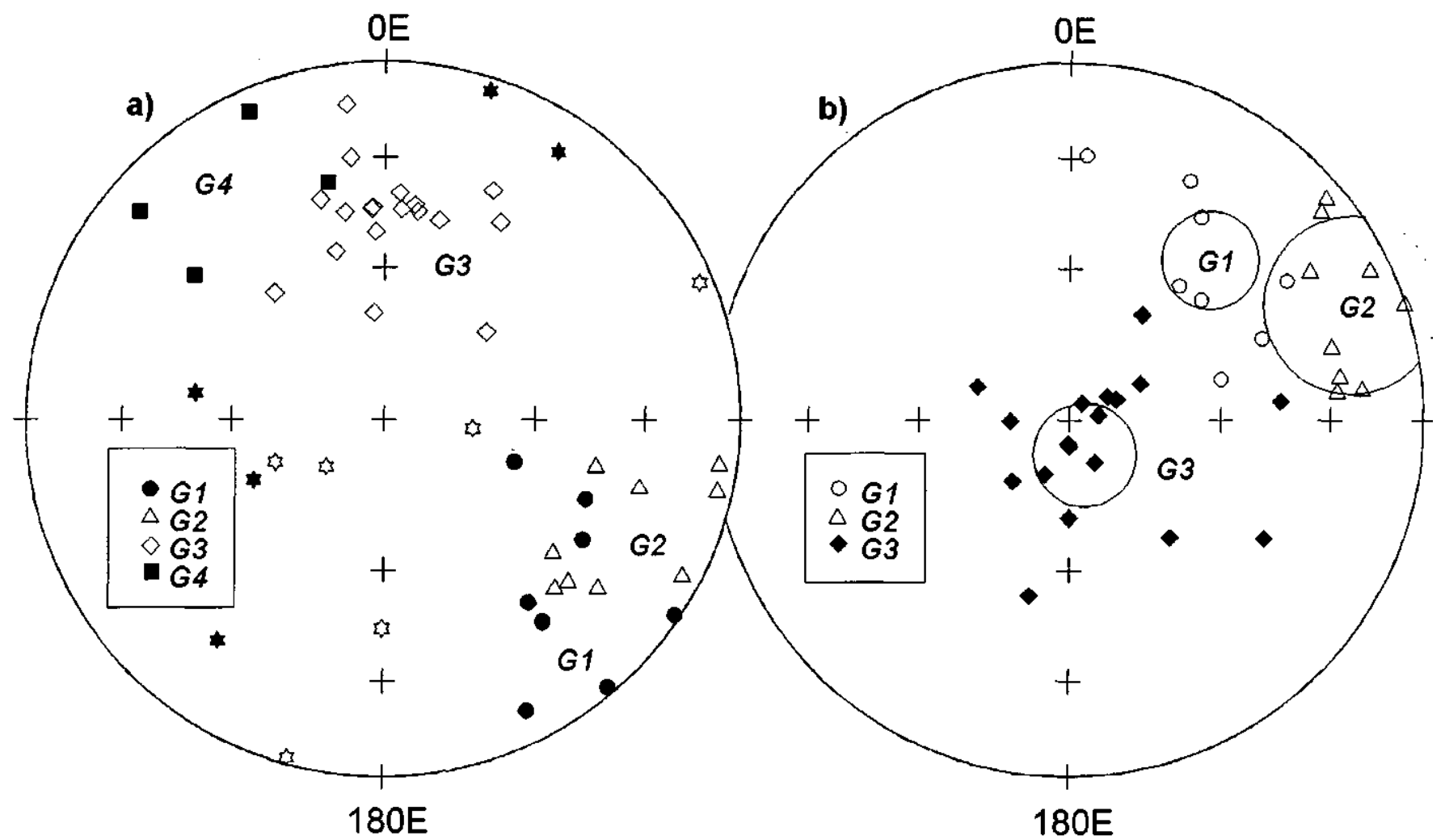

Figura 4-a) Direções médias de magnetização por sítio com $\sigma_{95} 30^{\circ}$. Símbolos cheios $=$ inclinações positivas; símbolos vazios $=$ inclinações negativas, b) Pólos geomagnéticos virtuais correspondentes aos grupos de direções Gl, G2 e G3 e respectivos pólos médios, indicados pelos círculos de confiança de 95\%. Símbolos cheios = latitudes positivas; símbolos vazios = latitudes negativas .

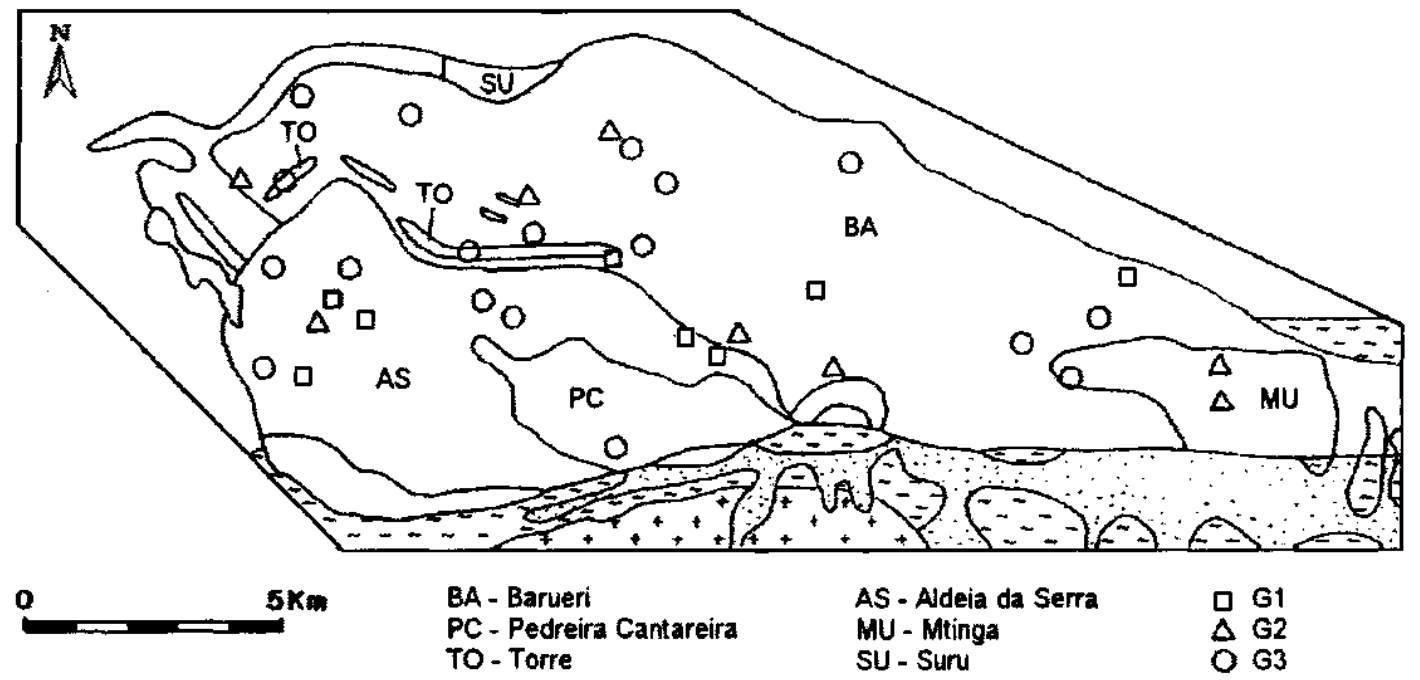

Figura 5 - Distribuições dos grupos de direções paleomagnéticas no Complexo Itaqui.

apesar da dispersão ainda persistente, pode-se identificar três agrupamentos distintos (Fig. 4): os grupos G1 e G2 com declinações no mesmo quadrante sudeste e com inclinações positivas e negativas, respectivamente, e o grupo G3 com declinação média próxima de zero e inclinações negativas. Outras direções puderam ser identificadas, mas não constituem grupos significativos.

Os grupos G 1 e $\mathrm{G} 2$ são menos definidos que o grupo G3 e poderiam constituir um único conjunto de direções características, mas, quando consideradas conjuntamente, a dispersão dos dados torna-se excessivamente grande. Um pequeno conjunto de dados (4 sítios) com direção nordeste e inclinações positivas (G4), assinalado na Fig. 4, pode constituir uma inversão de polaridade de $\mathrm{Gl}$ ou $\mathrm{G} 2$.
O Complexo Itaqui tem caráter poli-intrusivo e, portanto, pode admitir mais de uma componente de magnetização primária. Desta forma é necessário observar a distribuição dessas direções em relação às diferentes rochas do complexo. Na figura 5 , observa-se que, dos oito sítios do grupo Gl, cinco situam-se no granito Aldeia da Serra, dois no granito Barueri e um no granito Torre. As direções do grupo G2 associam-se preferencialmente ao granito Barueri. Observa-se que, dos nove sítios em que elas ocorrem, cinco situam-se no granito Barueri, dois no granito Mutinga, um no Pedreira Cantareira e um no granito Aldeia da Serra. O grupo G3 por sua vez, espalha-se por quase todas as unidades do complexo, não mostrando preferência por nenhuma específica. Estas distribuições não deixam claro se existe alguma 
Tabela l-Resultados paleomagnéticos do Complexo Itaqui.

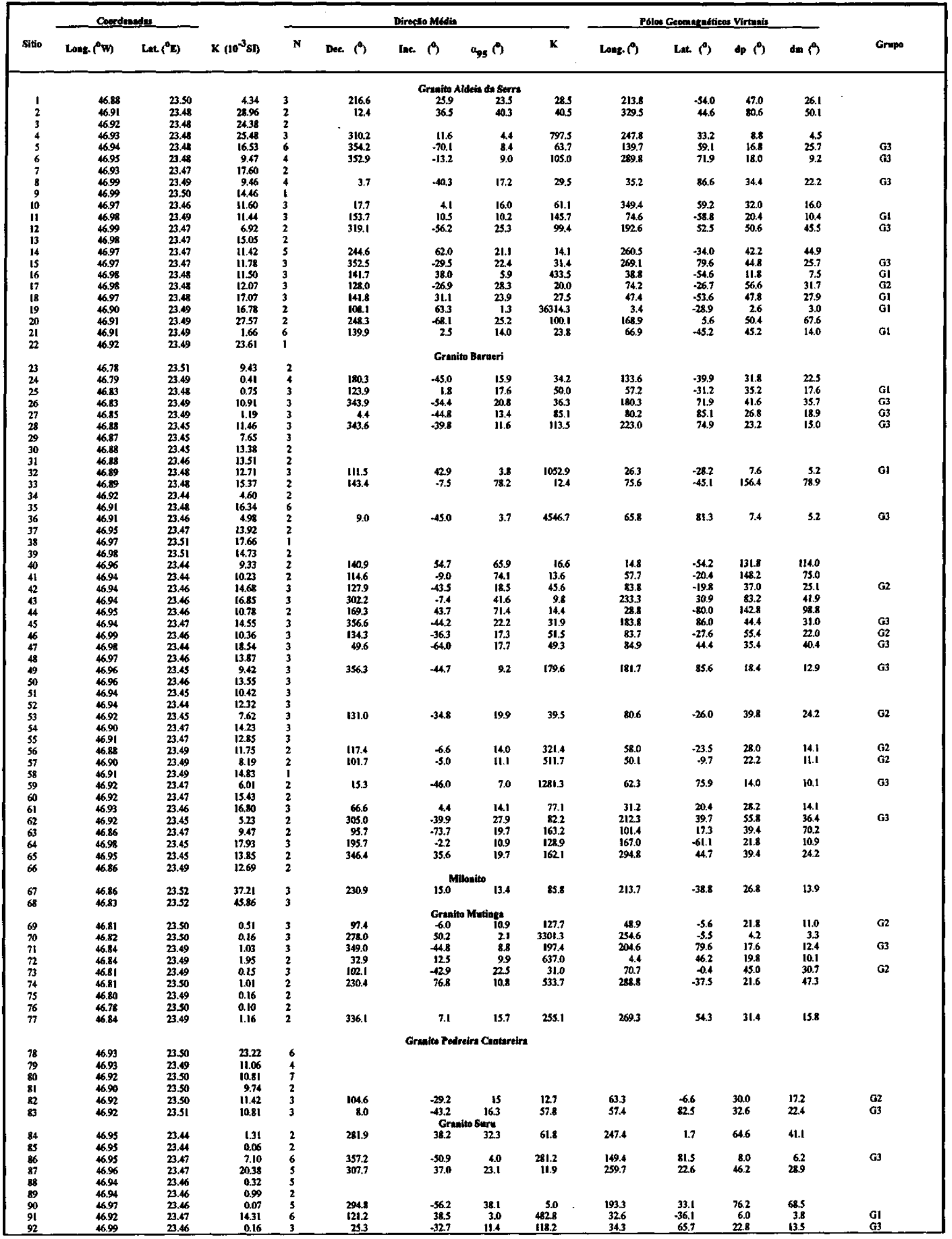



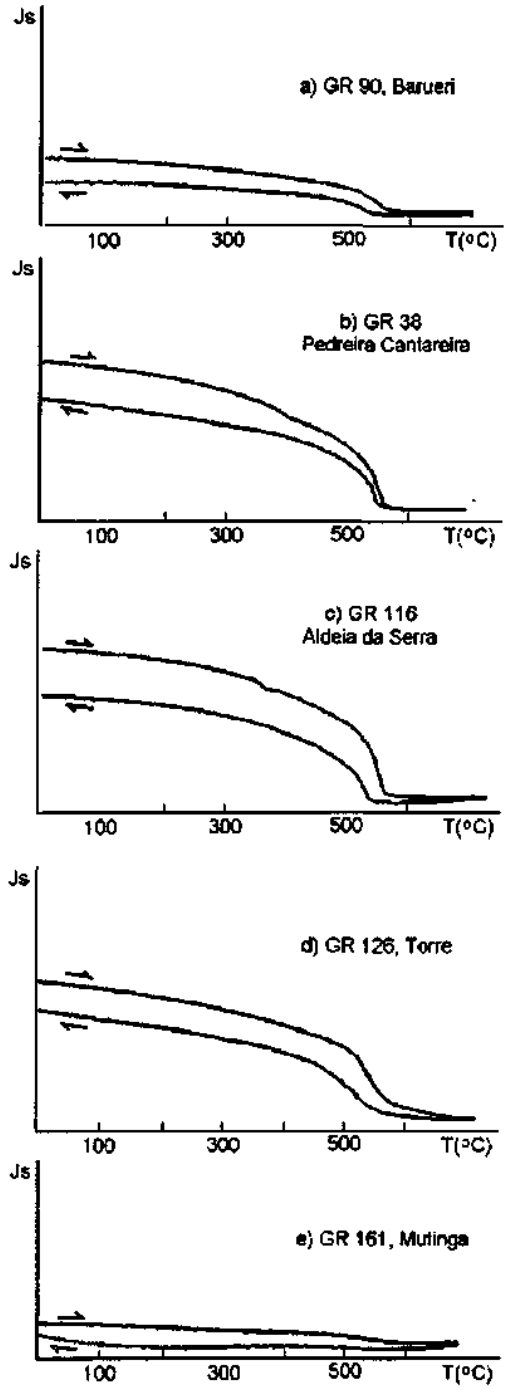

Figura 6 - Curvas termomagnéticas de amostras selecionadas das unidades do Complexo Itaqui. Js é a magnetização de saturação em unidades arbitrárias.

relação temporal entre elas ou se seriam de origem primária ou secundária.

IDENTIFICAÇÃO DA MINERALOGIA MAGNÉTICA Curvas termomagnóticas Foram obtidas curvas termomagnéticas de 25 amostras, cujos exemplos representativos são apresentados na Fig. 6. Observou-se que as temperaturas de Curie variam de $585^{\circ} \mathrm{C}$ a $600^{\circ} \mathrm{C}$, para as unidades Barueri, Pedreira Cantareira, Aldeia da Serra e Torre. Este intervalo de temperaturas é característico de titanomagnetita com baixo conteúdo de titânio (oxidação de alta temperatura), e que dominam a fração magnética dessas quatro unidades. Observa-se ainda, principalmente nas curvas das unidades Pedreira Cantareira e Aldeia da Serra, uma suave inflexão da curva, para temperaturas entre $300^{\circ} \mathrm{C}$ e $400^{\circ} \mathrm{C}$, evidenciando a presença de uma pequena quantidade de maghemita em algumas amostras. Estes resultados mostram que a mineralogia magnética dessas unidades do complexo é, em princípio, apropriada para preservar a magnetização remanescente térmica de origem primária.

A curva termomagnética referente ao granito Mutinga (Fig. 6e), mostra uma intensidade muito baixa de magnetização induzida (Js), e suaves inflexões nos intervalos de $200^{\circ} \mathrm{C}$ a $300^{\circ} \mathrm{C}$ e de $585^{\circ} \mathrm{C}$ a $600^{\circ} \mathrm{C}$. A baixa intensidade de magnetização induzida (Js) evidencia um comportamento dominantemente paramagnético, porém, os intervalos de temperaturas revelam pequenas quantidades de, respectivamente, maghemita e de titanomagnetita com baixo conteúdo de Ti.
Microscopia à luz refletida Os estudos da microscopia de luz refletida foram efetuados em seções polidas de 20 amostras das principais unidades do complexo. As seções analisadas mostraram que a titanomagnetita constitui a quase totalidade dos minerais opacos e ocorre preferencialmente em agrupamentos de cristais maiores, subordinadamente em grãos isolados, ou como inclusões diminutas em titanita, biotita e, mais raramente, em hornblenda. Quando em inclusões em titanita, a titanomagnetita, podem ou não conter intercrescimento de ilmenita.

A titanomagnetita é euédrica a subédrica, de tamanho variando entre $0,05 \mathrm{~mm}$ e $0,7 \mathrm{~mm}$, mais frequentemente de $0,1 \mathrm{~mm}$. Seus contatos com minerais adjacentes são, ora retos, ora irregulares e indicam que a titanomagnetita foi formada ao mesmo tempo que as fases máficas das unidades do complexo. Nos granitos Barueri, Pedreira Cantareira e Aldeia da Serra os agrupamentos de titanomagnetita podem ser constituídos localmente por ate mais de vinte cristais. No granito Torre esses agrupamentos são menos frequentes, e no granito Mutinga são raros.

Os cristais isolados de titanomagnetita estão frequentemente inclusos em biotita, titanita e às vezes em quartzo. Do mesmo modo como nos agrupamentos, os contatos com a titanita e a biotita, são retos e tambem curvos, mostrando mais uma vez a sua contemporaneidade com a fase máfica das unidades do complexo. As inclusões de titanomagnetita ocorrem predominantemente em cristais maiores de titanita e são mais frequentes nos granitos Barueri, Pedreira Cantareira e Aldeia da Serra. A textura de intercrescimento de ilmenita e titanomagnetita é pouco frequente mas, quando ocorre, a ilmenita é diminuta. As texturas do tipo composite e sandwich tanto podem ser geradas por oxidação, como também durante a cristalização magmática (Haggerty 1981)

Os estudos da mineralogia magnética do Complexo Itaqui, tanto os termomagnéticos, quanto os de microscopia à luz refletida, mostraram que o mineral responsável pela sua magnetização é a titanomagnetita. O tamanho dos grãos deste mineral magnético é máximo nos agrupamentos e na titanomagnetita isolada, enquanto grãos menores são, principalmente, aqueles inclusos os separados pelo intercrescimento de ilmenita. A estabilidade magnética do complexo pode estar ligada a essas dimensões. E possível que as dimensões dos cristais de titanomagnetita, aliado à baixa frequência intercrescimento de titanomagnetita e ilmenita, sejam responsáveis pela baixa estabilidade magnética de muitas amostras. As unidades que apresentaram os melhores resultados foram os granitos Barueri e Aldeia da Serra (Fig. 5), dois dos três granitos onde as inclusões de titanomagnetita em titanita são mais frequentes.

DATAÇÃO K-Ar Como acima descrito, os grupos de direções paleomagnéticas G1 e G2 associam-se principalmente às unidades Aldeia da Serra e Barueri, respectivamente, enquanto o grupo G3 ocorre por todas as unidades. Em vista disto, selecionou-se amostras das unidades Aldeia da Serra (GR-65), Barueri (GR-148) e Mutinga (GR-157) para análises radiométricas pelo método K-Ar empregando a biotita, em geral abundante nas três amostras. Os resultados constam da Tabela 2. As concentrações de $\mathrm{K}$ e ${ }^{40} \mathrm{Ar}$ situam-se dentro do limite de tolerância com a correção atmosférica não crítica, o que permite considerar as idades aparentes como de boa qualidade.

As idades obtidas (Tabela 2) são consideradas mínimas, uma vez que podem refletir a idade do resfriamento. Dados $\mathrm{Rb}-\mathrm{Sr}$ em rocha total (Tõpfener et al. 1996) indicam uma idade de $626 \pm 19$ Ma para o complexo. As idades da associação Cantareira, à qual pertence o granito Itaqui, são de $669 \pm 8 \mathrm{Ma} U-\mathrm{Pb}$ e $625 \pm 85 \mathrm{Ma} \mathrm{Rb}-\mathrm{Sr}$ (Tassinari 1988). Por outro lado, datações da associação Natividade, que também é de natureza tardi a pós-orogênica (Janasi \& Ulbrich 1991), forneceram uma idade de $570 \pm 50 \mathrm{Ma} \mathrm{Rb}-\mathrm{Sr}$ (Tassinari 1988).

DISCUSSÃO DOS RESULTADOS E CONCLUSÕES $\mathrm{Na}$

Tabela 3 são listadas as direções médias de magnetização correspondentes aos grupos Gl, G2 e G3 e os pólos paleomagnéticos respectivos. A distribuição dos pólos geomagnéticos virtuais (PGVs) de cada grupo está representada na Fig. 4b. Nota-se que essas distribuições não se superpõem significativamente, o mesmo acontecendo com o círculo de confiança dos pólos calculados. Esses pólos devem, portanto, ser considerados individualmente, para efeito de comparações com outros dados do Gondwana Ocidental. Embora exista um número considerável de pólos paleomagnéticos neoproterozóicos para a América do Sul, esses são muito dispersos (Correia 1994) e não permitem traçar uma curva de deriva polar aparente. A comparação será feita então, principalmente com aqueles de áreas cratônicas africanas, antes con- 


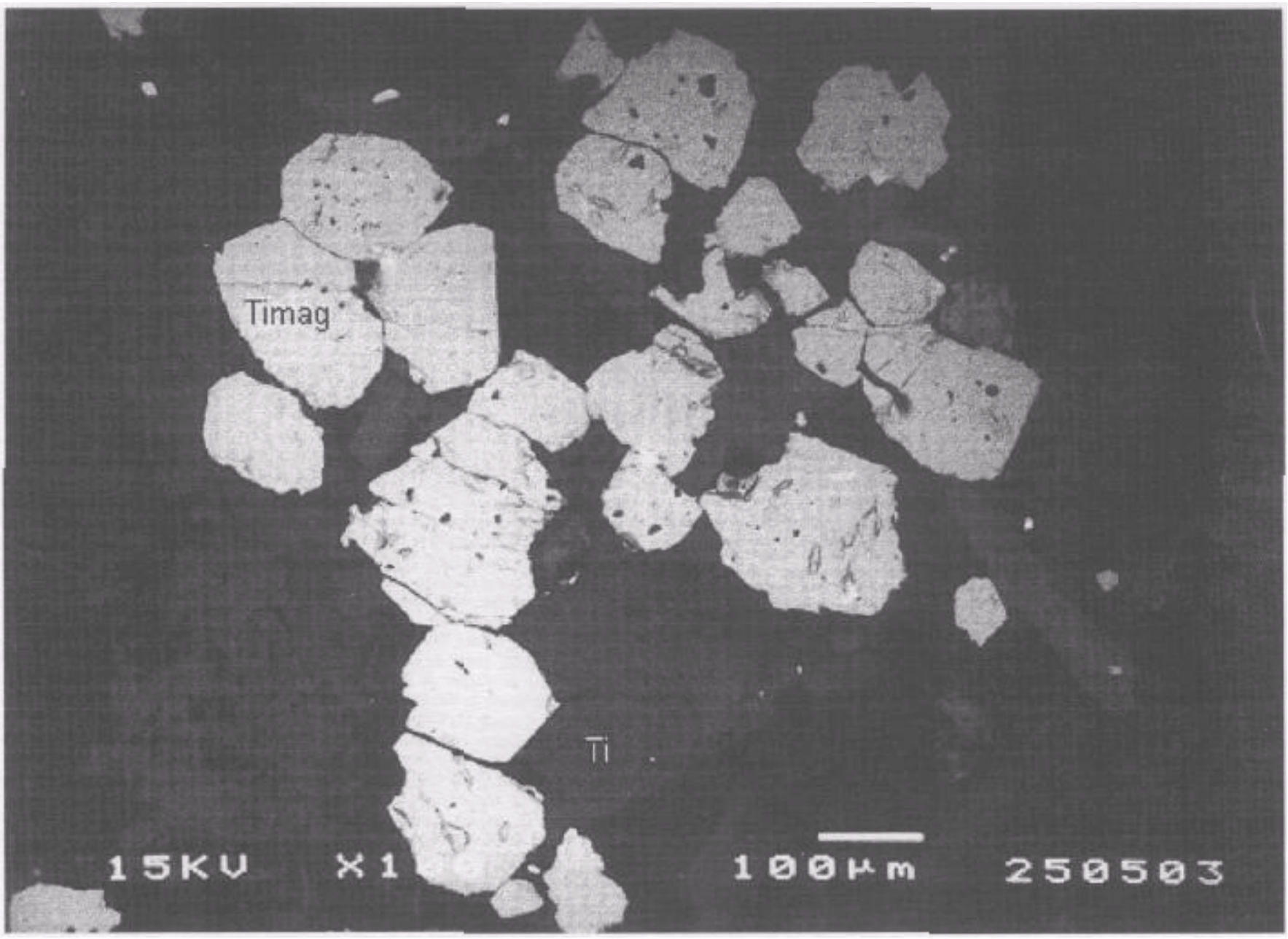

Figura 7 - Fotomicrografia a luz refletida de amostra do Complexo Itaqui mostrando um agregado de titanomagnetita (Timag).

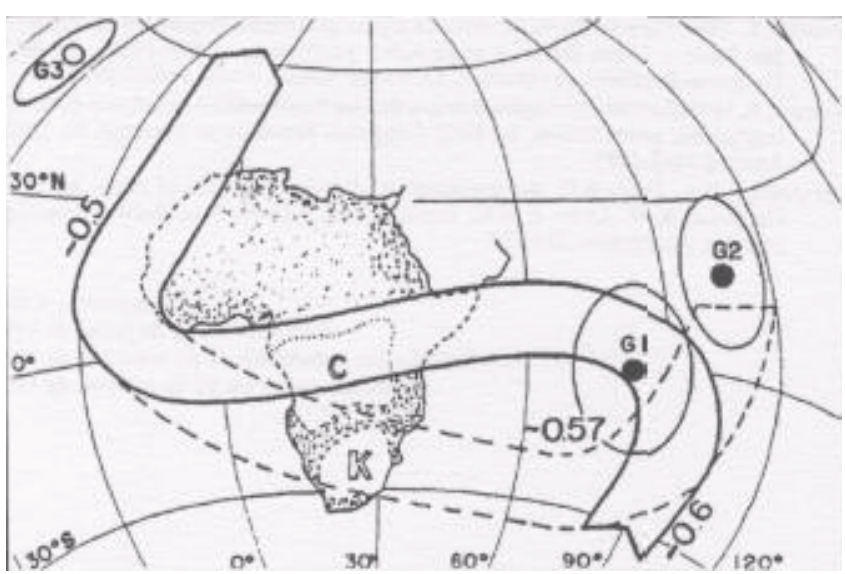

Figura 8 - Curvas de deriva polar aparente de McWilliams \& Kröner (1981) para os crátons do Congo e Kalahari (linha cheia) e de D'Agrella Filho (1992) para o continente africano (linha tracejada). As idades indicadas nas curvas são dadas em Ga. Pólos Gl, G2 e G3 deste trabalho, rotacionados para a África, estão representados pelos respectivos círculos de confiança. Símbolos cheios e vazio indicam hemisfério superior e inferior, respectivamente.

tíguas. Para tanto, os pólos G1, G2 e G3 foram rotacionados para a África, segundo o pólo de rotação proposto por Martin et al. (1981). Uma análise dos dados paleomagnéticos realizada por Mc Williams \& Kröner (1981), permitiu a construção da curva de deriva polar dos crátons do Congo e Kalahari e do cinturão Damara, no intervalo de 600 a 500 Ma (Fig. 8). Na mesma figura está também representada a
Tabela 2 - Resultados K-Ar de amostras das unidade Aldeia da Serra, Barueri e Mutinga.

\begin{tabular}{|c|c|c|c|c|c|c|}
\hline Amostra & Sitio & Unidade & $\% \mathrm{~K}$ & $\begin{array}{l}\text { Ar rad. } \\
(10-6 \mathrm{ceSTP} / \mathrm{g})\end{array}$ & Ar atm. & $\begin{array}{l}\text { Idade } \\
\text { (Ma) }\end{array}$ \\
\hline GR 65 & 16 & AS & 6.9367 & 170.43 & $6 \pi$ & $542 \pm 7$ \\
\hline GR 148 & 28 & BA & 7.6640 & 184.73 & 6.55 & $533 \pm 6$ \\
\hline GR 157 & 73 & MU & 7,3826 & 170,67 & 5.36 & $525 \neq 7$ \\
\hline
\end{tabular}

Tabela 3 - Direções médias e pólos geomagnéticos virtuais do Complexo Itaqui.

\begin{tabular}{|c|c|c|c|c|c|c|c|c|c|}
\hline \multirow[b]{2}{*}{ Grupo } & \multicolumn{4}{|c|}{ Direcsles Median } & \multirow[b]{2}{*}{$\mathrm{N}$} & \multicolumn{4}{|c|}{ Pólé Foletenagaticea } \\
\hline & $\begin{array}{c}\text { Det. } \\
0\end{array}$ & $\begin{array}{l}\text { Int. } \\
0.7\end{array}$ & $k$ & $\begin{array}{l}a_{a t} \\
07\end{array}$ & & $\begin{array}{l}\text { Long } \\
8\end{array}$ & $\frac{1.44}{(1)}$ & $k$ & $a_{n}$ \\
\hline GI & 132.5 & 29.3 & 10 & $\frac{18.1}{18.1}$ & 8 & 41.0 & $\frac{102}{-142}$ & 15 & 15 \\
\hline 02 & 115.3 & 26.4 & 16 & 13.3 & 9 & 67.8 & +16.6 & 23 & II \\
\hline G3 & 356.6 & -456 & 17 & 8.5 & 18 & 1566 & 83.6 & 14 & 10 \\
\hline
\end{tabular}

curva da África, no mesmo intervalo de tempo, proposta por D'Agrella Filho (1992). Para comparação com essas curvas, os pólos G1, G2 e G3 rotacionados para a África, foram representados juntamente com os seu respectivos círculos de confiança $\left(\alpha_{95}\right)$. Observa-se que os pólos G 1 e G2 (540-520 Ma) são coerentes com as curvas de deriva propostas, para idades próximas a $570 \mathrm{Ma}$. O pólo G2, apesar de um pouco mais afastado do que Gl, seu círculo de confiança intercepta a curva de linha tracejada, indicando boa concordância do pólo G2, com a curva de D'Agrella para o continente africano.

O pólo G3 por sua vez, foge totalmente dos limites da área destas curvas de deriva polar, não podendo ser comparado com as mesmas. A posição deste pólo parece sugerir uma remagnetização, pois é comparável aos pólos paleomagnéticos da América do Sul para o Mesozóico (p. ex., Raposo \& Ernesto 1995). O evento termo-tectônico 
que deu origem à abertura do Atlântico Sul, no Mesozóico, pode ter sido o responsável por uma magnetizacão parcial do Complexo Itaqui, embora isto não se evidencie pelas datações K-Ar. Não é claro como seria possível ter havido remagnetização total das amostras sem que houvesse perda total de Argônio. As curvas termomagnéticas revelam que os cristais de magnetita teriam a magnetização inicial desbloqueada a temperaturas acima de $500^{\circ} \mathrm{C}$, implicando em que, se houve aquecimento, este ocorreu a temperaturas inferiores à de abertura do sistema Argônio, mas durante um intervalo de tempo suficientemente longo para que houvesse remagnetização total. Esta hipótese, entretanto, tem que ser vista com cautela, uma vez que parte do minerais magnéticos teriam, ainda assim, preservado componentes de magnetização antigas.

Embora a quantidade e qualidade dos dados limitem a confiabilidade dos pólos paleomagnéticos aqui determinados, é possível sugerir que existam duas direções de magnetização primária, o que seria coerente com o caráter poli-intrusivo do Complexo Itaqui (Wernick \& Ferreira 1991). Como mostrado na figura 5, a direção Gl predomina na unidade Aldeia da Serra e a direção G2 na unidade Barueri. No modelo evolutivo do Complexo Itaqui, Ferreira (1991) considera que a unidade Barueri é anterior à unidade Aldeia da Serra. A posição dos pólos Gl e G2 (Fig. 8) estaria de acordo com essa ideia e, neste caso, o pólo $\mathrm{G} 2$ seria ligeiramente mais antigo que $\mathrm{Gl}$.

Agradecimentos Ao CEPEGEO/USP, em especial ao Prof. Wilson Teixeira, pelas determinações radiométricas K-Ar, a Cláudio J. Ferreira pelo apoio nos trabalhos de campo e valiosas discussões, a Roberto Siqueira pelo apoio no laboratório e na parte de computação, como também a Manoel D'Agrella Filho, pela colaboração e proveitosas discussões. O manuscrito foi significativamente melhorado com a contribuição de dois revisores anônimos. A pesquisa contou com o apoio financeiro do PADCT/FINEP.

\section{Referências}

Archanjo, C.J.; Bouchez, J.L.; Corsini, M.; Vouchez, A. 1994. The Pombal granite pluton: magnetic fabric, emplacement and relationship with the Brasiliano strike-slip setting of NE Brazil (Pariba State). J. Struct Geol, 16:323-335.

Bouchez, J.L.; Gleizes, G.; Djouadi, T.; Rochette, P. 1990. Microstructure and magnetic susceptibility applied to emplacement kinematics of granites: the example of the Foix pluton (French Pyrenees). Tectonophysics, 184:157-171.

Brito Neves, B.B.; Cordani, U.G. 1991. Tectonic evolution of the South America during the Late Proterozoic. Precambion Res., 53:23-40.

Correia, P.B. 1994. Paleomagnetismo e Anisotropia de Susceptibilidade Magnética do Complexo Intrusrvo Itaqui, Estado de São Paulo, Inst. Astronômico e Geofísico, Universidade de São Paulo, São Paulo, Tese de Doutoramento, $115 \mathrm{pp}$.

D'Agrella Filho, M.S. 1992. Paleomagnetismo de enxames de diques máftcos proterozóicos e rochas do embasamento do Craton do São Francisco. Inst. Astronômico e Geofísico, Universidade de São Paulo, São Paulo, Tese de Doutoramento,

D'Agrella Filho, M.S.; Pacca, I.G. 1988. Paleomagnetism of the Itajai. Castro and Bom Jardim groups from southern Brazil. Geophys. J., 93:365-376.

Ellwood, B.B.; Whitney, J.A. 1980. Magnetic fabric of the Elberton granite, northeast Georgia. J. Geophys. Res., 85:1481-1486.

Ferreira, C. J. 1991. Geologia, petrogrqfla e tipologia de zircão da Suite Itrusiva Itaqui, Barueri $(S P)$. Inst de Geociências e Ciências Exalas, Universidade Estadual Paulista, Rio Claro. Dissertação de Mestrado.

Ferreira, C. J. 1996. Geoquimica e análise da deformação do complexo Itaqui, SP: Evolução de granitos cálcio-alcalinospoli-intrusivos. Inst. de Geociências e Ciências Exatas, Universidade Estadual Paulista, Rio Claro. Tese de Doutoramento, 272 pp.

Ferreira, C.; Wemick, E. 1991. Petrografia da Suite Intrusiva Itaqui, SP. In: SBG/Núcleo São Paulo, Simpósio de Geologia do Sudeste, Atas, 121-129.

Fisher, R.A. 1953. Dispersion on a sphere. Proc. Roy. Soe. London ser.A, 217:295-305.

Haggerty, S.E., 1981. Oxidation of opaque mineral oxides in basalts. In: D. Rumble (ed.) Reviews in Mineralogy (vol.3), Oxide Minerais: chapter 4, Mineralogical Society of America, Washington D.C.

Hattingh, P. J. 1990. Palaeomagnetism of granites in the Bushveld Complex. S. Afr. J. Geol., 93:519-524.

Ishihara, S. 1981. The granitoid series and mineralization. Econ. Geol. 75th Anivers.:458-484

Janasi, V.A.; Ulbrich, H.H.G.J. 1991. Late Proterozoic granitoid magmatism in the state of São Paulo, southeastem Brazil. Precambrian Res., 51:351-374

Kirshvink, J.L. 1980. The least-squares line and plane and the analysis of paleomagnetic data. Geophys. J.R.Astr. Soe. 62:699- 718.

Magalhães, M.S.; Dall'Agnol, R.1992. Rev. Brasil. Geoc., 22(2): 184-197.

Magalhães, M.S.; DalPAgnol, R.; Sauck, W.A.; Luiz, J.G. 1994. Rev. Brasil. Geoc. 24(3):139-149.

Martin, A.K.; Hartnady, C.J.H.; Goodlad, S.W. 1981. A revised fit of South America and South Central Africa. Earth Planei. Sci. Lett., 54:293-305.
McWilliams, M.O.; Kröner, A. 1981. Paleomagnetism and tectonic evolution of the Pan-African Damara Belt, Soutern África. J. Geophys. Res., 86:5147-5162.

Olivier, P.; Archanjo, C.J. 1994. Magnetic and magmatic structures of the Emas granodioritic pluton (Cachoeirinha belt, NE Brazil): Relationships with Pan-African. strike-alip fault system. Tectonophysics., 229:230-250.

Raposo, M.I.B.; Ernesto, M. 1995. An early Cretaceous paleomagnetic pole from Ponta Grossa dykes (Brazil): implications for the South America Mesozoic APWP. J. Geophys. Res., 100 (B10):20,095-20,109.

Renne, P.R.; Onstott, T.C.; João, X.S.J. 1988. An. VII Latin-American Geológical Congress, Belém, Pará, v. 1:348-362.

Tassinari, C.C.G., 1988. As idades das rochas e dos eventos metamórftcos da porção sudeste do Estado de São Paulo e sua evolução crustal. Inst. de Geociências, Universidade de São Paulo, Tese de Doutoramento, 236 pp.

Tõpfener, C., Ladwig, L., Weber-Diefenbach, K., 1996. Rb/Sr systematikperaluminõserm metaluminöser und peralkaliner Brasiliano-granitoid im südlichen Ribeira mobile belt, Brasilien. Terra Nostra, 8:140-141.

Wemick, E.; Ferreira, C.J. 1991. Estruturas, arquitetura e evolução do complexo granitóide Itaqui, SP. Geociências, UNESP, 12:89-109.

Wemick, E.; Galembeck, T.M.B. 1985. Contribuição à caracterização de granitóides do Estado de São Paulo através do mineral acessório zirconita. In: SBG/Núcleo São Paulo, Simpósio Regional de Geologia, 5, Atas, 1:119-132.

Wemick, E.; Galembeck, T.M.B. 1986. Caracterização do plutonismo granitóide do ciclo Brasiliano no Estado de São Paulo.In: SBG, Congr. Brasi. Geol., 34, Goiânia, Anais, 3:1369-1382.

Wernick, E.; Galembeck, T.M.B. 1987. Evolução geotectônica durante o Proterozóico Superior no Estado de São Paulo: uma contribuição através da análise do magmatismo granitóide. In: SBG/Núcleo São Paulo, Simpósio de Geologia, 6, Rio Claro, Atas, 1:191-204.

Wemick, E. 1984. Caracterização genética de alguns granitóides Brasilianos do Estado de São Paulo e Minas Gerais e implicações geotectônicas preliminares. In: SBG, Congresso Brasileiro de Geologia, 33, Rio de Janeiro, Anais, 6:2902-2918.

Wernick, E. 1990. Zoneamento regional de granitóides brasilianos no sudeste/sul do Brasil: implicações geotectônicas. In: SBG, Congresso Brasileiro de Geologia, 36, Natal, Anais, 4:1668-1683.

Zijderveld, J.D.A. 1967. A.C. demagnetization of rocks: Analysis of reults. In: W.D. Collinson, K.M. Creer \& S.K. Runcorn (eds.) Methods in Palaeomagnetism, Elsevier, Amsterdam, 254-286.

Manuscrito A-993

Recebido em 16 de junho de 1998

Revisão dos autores em 30 de setembro de 1998 Revisão aceita em 05 de outubro de 1998 